\title{
Finite Element Analysis of the Effect of Fin Geometry on Thermal Performance of Heat Sinks in Microelectronics
}

\author{
EKPU, M \\ Department of Mechanical Engineering, Delta State University Abraka, Oleh Campus, Delta State, Nigeria. \\ *Email: ekpum@delsu.edu.ng
}

\begin{abstract}
Heat sinks are commonly used for the dissipation of heat in microelectronics packages. The choice of optimal heat sinks configuration largely depends on the market demand and thermal performance. Hence, having the right heat sinks configuration is vital to the overall thermal durability of the microelectronics package. This paper investigates the thermal resistance and efficiency of heat sink fins geometry in microelectronics application. This study investigates the shapes of six (square, rectangular, triangular, hexagonal, circular, and elliptical) different heat sink fins on thermal performance. ANSYS finite element design software was used to create the 3D models and meshed between $5-20 \%$ of the initial mesh size. Transient thermal conduction analysis was used in analysing the heat sinks. The results obtained demonstrated that the more number of elements in the mesh (or the finer the mesh) the better the convergence of the numerical solution. The results also showed that the rectangular shaped heat sink fins exhibited better thermal capabilities than the other shaped fins, by having a maximum temperature of about $42.5^{\circ} \mathrm{C}$, thermal resistance of about $0.244 \mathrm{~K} / \mathrm{W}$, and thermal efficiency of about $50 \%$.
\end{abstract}

\section{DOI: DOI: https://dx.doi.org/10.4314/jasem.v23i11.24}

Copyright: Copyright (C) 2019 Ekpu. This is an open access article distributed under the Creative Commons Attribution License (CCL), which permits unrestricted use, distribution, and reproduction in any medium, provided the original work is properly cited.

Dates: Received: 07 October 2019; Revised: 11 November 2019; Accepted: 24 November 2019

Keywords: heat sink; fin geometry; thermal resistance

Managing heat in microelectronics applications is crucial to the overall reliability of the electronics system. When heat is not managed properly the electronics system is likely to fail or will fail with time. The increase in the demand of miniaturised electronic devices has further increased the challenge of managing heat in such devices. Heat sinks have been widely employed for dissipating heat in microelectronics components (Ekpu 2018; Wan et al, 2011; Ekpu et al, 2011). Several researchers have studied the heat transfer of different heat sink configurations in the open literature and a few of such research findings will be presented in this paper. Yang and Peng (2008) researched on numerical study of pinfin heat sink with un-uniform fin height design. The research found out that by increasing the fin height near the centre of the heat sink, the junction temperature will be reduced. Naphon and Sookkasem (2007) carried out an investigation on heat transfer characteristics of tapered cylinder pin fin heat sinks. The investigation showed that the numerically predicted results were in reasonable agreement with the experiment conducted. In another study, Maveety and Jung (2000) investigated the design of an optimal pin-fin heat sink with air impingement cooling. The study found out that the predicted thermal resistance of the heat sink agrees with those obtained from experiments. In the following references (Yang and Peng, 2009; Maveety and Jung, 2002; Kreutz, 2000; Luo et al, 2009; Kulkarni and Das, 2005), more information on the role of heat sinks and their configurations in the transfer of heat in microelectronics applications are recorded.
The present study focused on thermal conduction of different shapes of heat sinks fins. The fin shapes studied are squared, rectangular, triangular, hexagonal, circular and elliptical. This research is aimed at comparing different heat sink geometries in a single investigation.

\section{MATERIALS AND METHODS}

Model Description and Loads: This section presents the designed models used for the finite element analysis. All models were created using ANSYS version 13 finite element design software. Each simplified model comprised of a chip with a dimension of $10 \times 10 \times 1 \mathrm{~mm}^{3}$, a heat sink base with a dimension of $31.24 \times 31.24 \times 2.03 \mathrm{~mm}^{3}$, and 81 fins. The heat sink arrangement was inspired by literature data on the Pentium III heat sink studied previously by (Ekpu et al, 2013), although slight geometric modifications have been incorporated for ease of comparison of the different model geometries. The choice of dimensions, for different fin shapes was informed by keeping the volume $\left(\mathrm{V}_{\mathrm{f}}\right.$ - volume of fins $)$ the same for all fin shapes. Table 1 shows the dimensions of the square, rectangular, triangular, hexagonal, circular, and elliptical heat sink fins. The ones chosen here have been chosen due to ease of manufacturability. Also the equal volume for all the different shapes considered ensures for objective comparison of the results. The top view of the heat sink documented for all the different shapes of fins are presented in Fig. 1. 
Boundary Conditions and Materials: Aluminium heat sinks and silicon chips with thermal conductivities of $237.5 \mathrm{~W} / \mathrm{mK}$ and $148 \mathrm{~W} / \mathrm{mK}$ (derived from in-built ANSYS material models) respectively were used. In this study transient thermal analysis was carried out (the analysis was chosen to show the capability of the ANSYS software used). Heat loss due to radiation is neglected while conduction and convection were considered. A heat source of $80 \mathrm{~W}$ was used in order to represent the power used by most microelectronics device. These load values were chosen for this study and a further investigation can be taken to access the effect of different loads on the numerical solution. Also, a convective coefficient for natural convection was applied to all heat sinks (the convective equation of the outer surfaces of the heat sink can be found in Ekpu 2018). The thermal conduction in this study is governed by the Fourier equation given in (Ekpu et al, 2012; Incropera et al, 2007). In addition, a 3dimensional analysis was conducted for the heat sinks. The maximum temperature of the fins, thermal resistances of the fins, and thermal efficiency of the fins were investigated in this study.

\begin{tabular}{|c|c|c|c|c|c|}
\hline Shape of Fin & Length (mm) & Width (mm) & Height $(\mathrm{mm})$ & Diameter (mm) & Volume of Fin $\left(\mathrm{mm}^{3}\right)$ \\
\hline Square & 2 & 2 & 10 & - & $L^{2} h=40$ \\
\hline Rectangular & 2.5 & 1.6 & 10 & - & $\mathrm{L} \times \mathrm{b} \times \mathrm{h}=40$ \\
\hline Triangular & 2.5 & 3.2 & 10 & - & $1 / 2(b h L)=40$ \\
\hline Hexagonal & 1.241 & - & 10 & - & $2.5981 \mathrm{~L}^{2} \mathrm{~h}=40$ \\
\hline Circular & - & - & 10 & 2.257 & $\pi \mathrm{d}^{2} \mathrm{~h} / 4=40$ \\
\hline Elliptical & $1.273 *$ & $1 *$ & 10 & - & $\pi \mathrm{Lbh}=40$ \\
\hline
\end{tabular}

\section{RESULTS AND DISCUSSIONS}

Mesh Dependency Study: In order to deploy the finite element method for study of fin shapes on thermal response of heat sinks, it is vital that all designed models are adequately meshed. Adequate meshing demands a mesh dependency study of predicted model parameters. For the purpose of this study, the mesh dependency study was designed to assess the effect of changing mesh density on the thermal resistance of the heat sinks. Thermal resistance is directly proportional to temperature difference and inversely proportional to the supplied heat load. For increasing mesh density, it is expected that the thermal resistance will result into a convergent solution whose numerical value is independent of the mesh quality. The mesh that results in such convergent solution is therefore chosen as the adequate mesh for this study. Fig. 2 shows the plot of thermal convergence versus logarithm of the total number of elements per given mesh. Further mesh dependency study was carried out on maximum temperatures in the system. The result is shown in Fig. 3. It was observed for all models that the influence of the mesh artefacts on the temperature was reduced or became insignificant for mesh above 100000 elements which are about $40 \%$ of the initial mesh size. This means that the temperature became stable when the mesh was above 100000 elements (or less than $40 \%$ of the initial mesh size). It is important to note that all models used in this study were meshed between $700000-8500000$ elements (which are about 5\% $20 \%$ of the initial mesh size) provided the computing machine could solve the resulting solution without running out of memory
Fins Shape and Conduction Profile: The temperature contour plots of the top view of the heat sink fins of are presented in Figs. 4. The contour plots of temperature distributions shown in Figs. 4 showed that the heat concentration is highest around the centre of the heat source. This is expected since the power source (the chip) is centrally located hence dissipation will begin from centre and spreads outwards as confirmed by the contour plots. As a consequence, the fins around the centre of the heat source will have shown the maximum temperature recorded amongst the other fins.

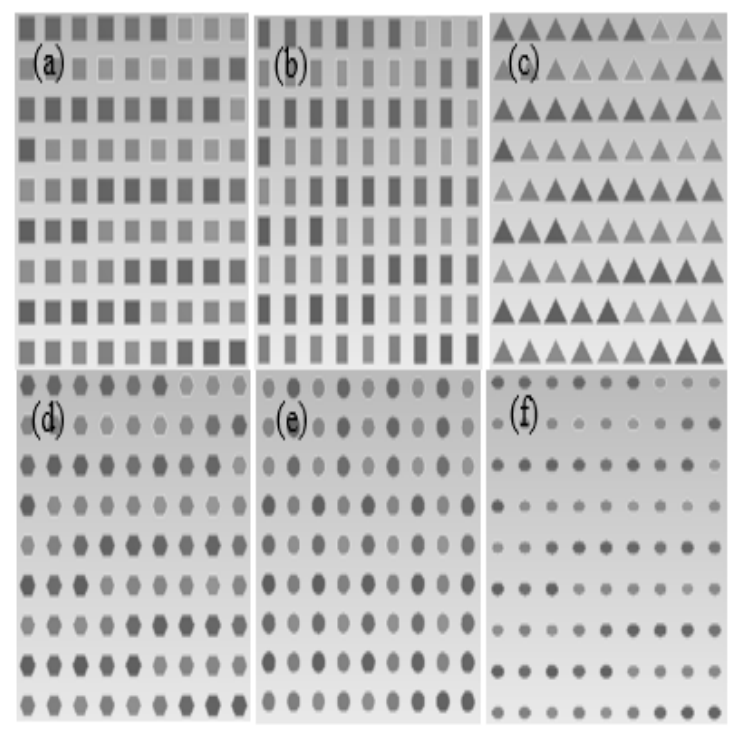

Fig. 1: Fins shapes (a) square; (b) rectangular; (c) triangular; (d) hexagonal; (e) circular; (f) elliptical 


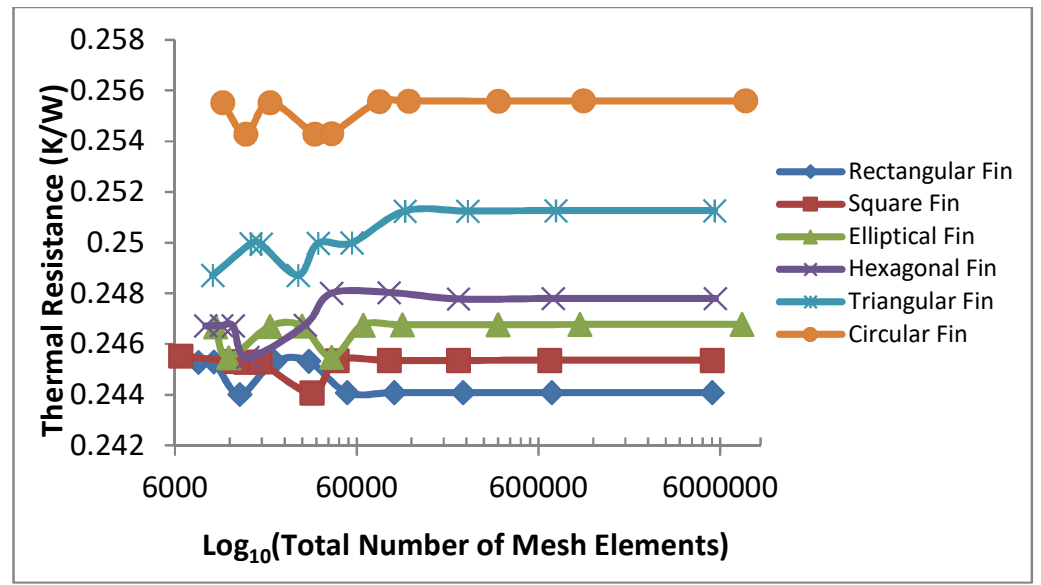

Fig. 2: Thermal resistance of the total mesh elements for the different heat sink shapes

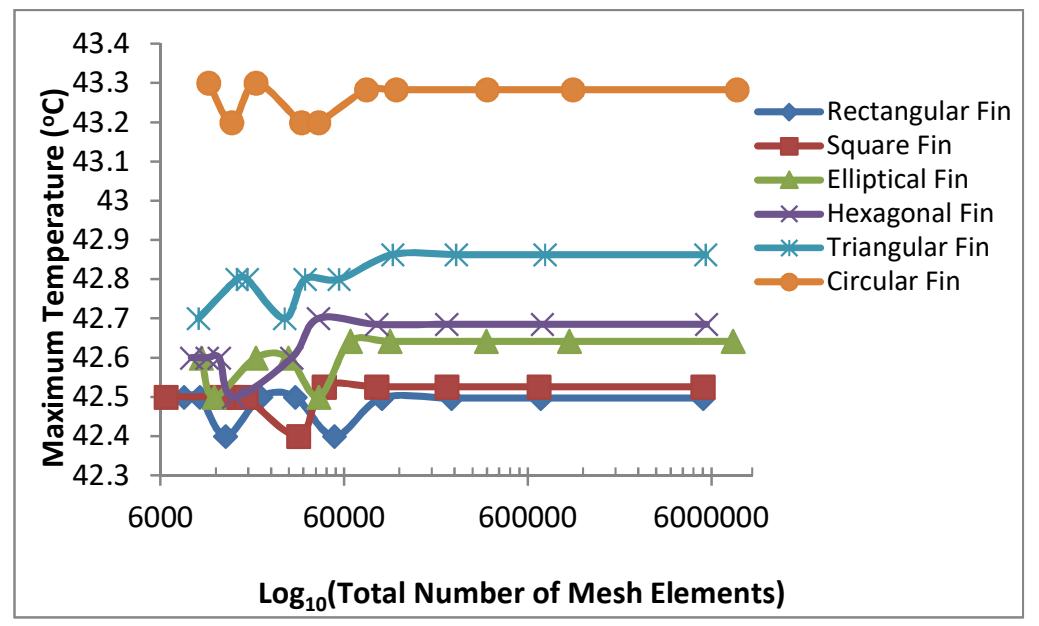

Fig. 3: Maximum temperature of the total mesh elements for the different heat sink shapes

Another important conclusion that can be derived based on contour plots shown in Fig. 4 is that the heat flow is determined significantly by the shape of the fins. In all shapes, concentric circles of heat map were seen to initiate from the centre (power source/chip) of the heat sink and flow outward as expected, since the fin arrangements are regular. Therefore, the heat maps will be regular hence the concentric circles. This is an important observation as it suggests that an intelligent arrangement of the fins can help conduct the dissipated heat in the preferred direction, hence isolating hot and cold zones which should help a microelectronics product developer in their designs. Thermal Resistance and Efficiency Analysis: The maximum temperature of the different fins shapes taken from the base of the heat sink are presented in Fig. 5. Fig. 5 showed that the rectangular shaped fins recorded the lowest maximum temperature while circular shaped fins recorded the highest maximum temperature. The thermal resistance $(R)$ of the fins is calculated using Eq. 1.

$$
R=\Delta T / Q
$$

Where $\Delta T=T_{m}-T_{a}$, and $T_{m}$ and $T_{a}$ are the maximum and ambient temperature respectively. $Q$ is the heat flow in watts (W). The results of the numerically derived thermal resistances are presented in Fig. 6. The rectangular shaped fins recorded the lowest thermal resistance, followed very closely by the square shaped fins while circular shaped fins recorded the highest thermal resistance as shown in Fig. 6. Fig. 7 presents the thermal efficiency of the different fin shapes. In Fig. 7, it was observed that the rectangular shaped fins have the highest thermal efficiency but closely followed by square shaped fins while circular shaped fins recorded the lowest thermal efficiency. In this analysis, it could be deduced that rectangular shaped heat sink fins will perform better in the conduction of heat, followed by square shaped fins while elliptical shaped fins will least conduct heat based on the criteria of this investigation. 


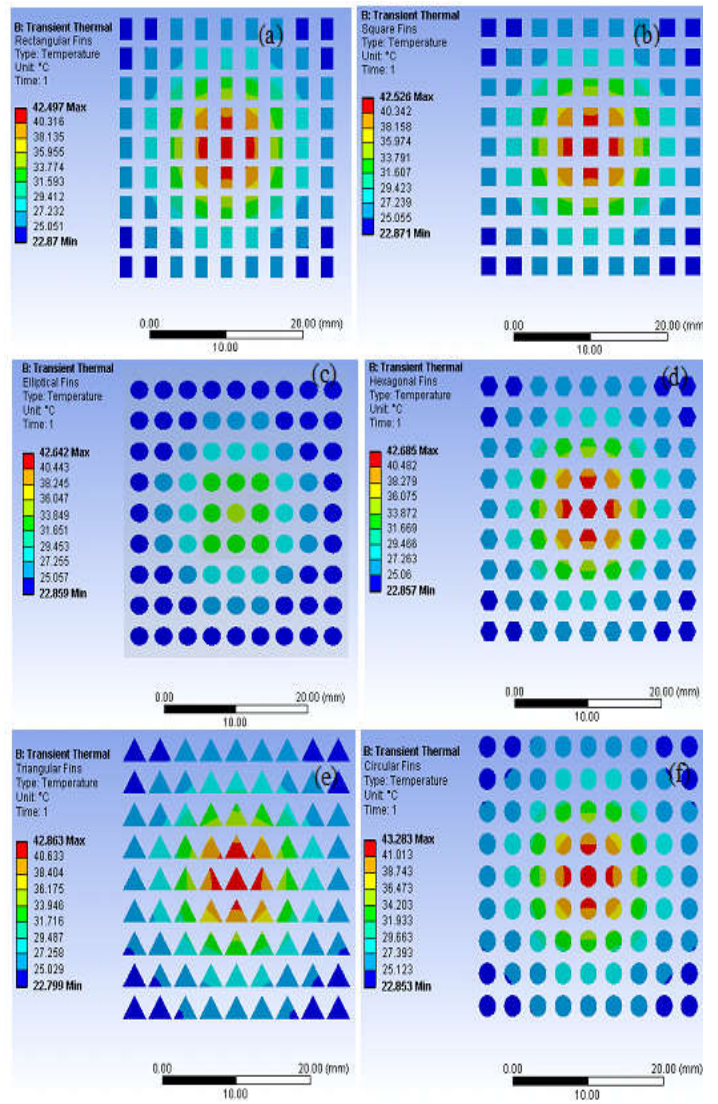

Fig. 4: Temperature Contour Plots for Case Study I (Time is in seconds): (a) Rectangular Fins; (b) Square Fins; (c) Elliptical Fins

(d) Hexagonal Fins; (e) Triangular Fins; (f) Circular Fins

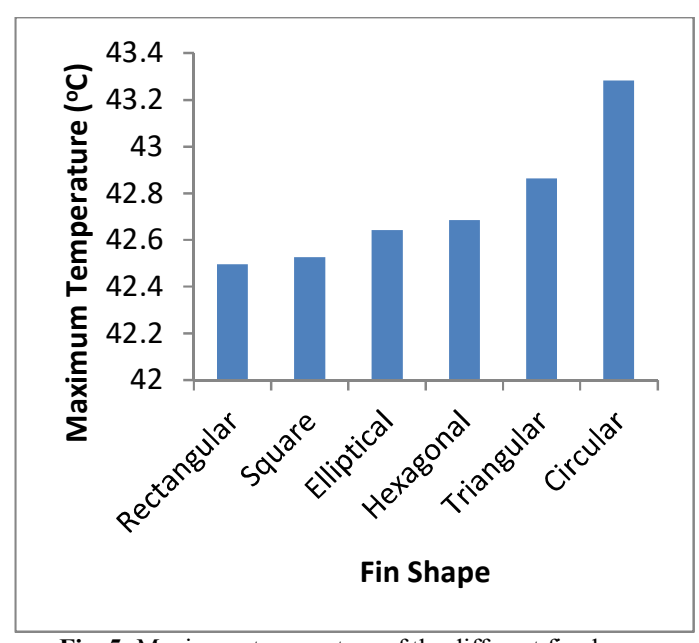

Fig. 5: Maximum temperature of the different fin shapes

Conclusions: The thermal analyses of microelectronics heat sinks have been presented in this research. The shapes of different heat sink fins namely: square, rectangular, triangular, hexagonal, circular, and elliptical were investigated. From this research it could be concluded that rectangular shaped fins exhibited better thermal performance characteristics than the other shaped fins. However, the choice of a particular heat sink may largely depend on the design engineer and market demand.

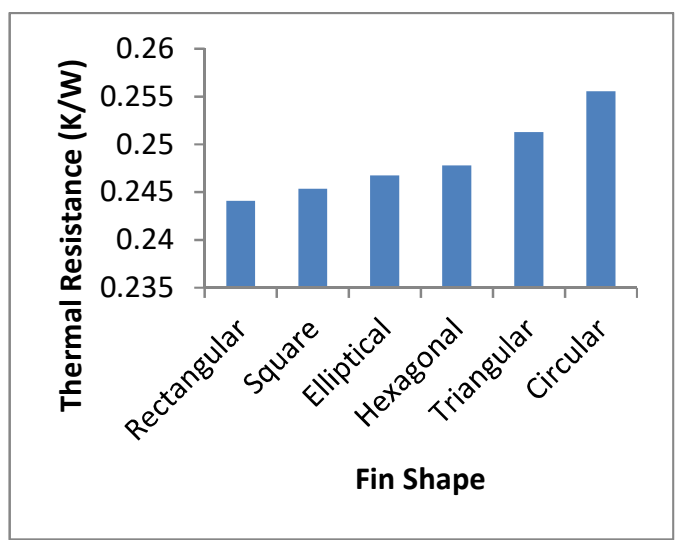

Fig. 6: Thermal Resistance of the different fin shapes

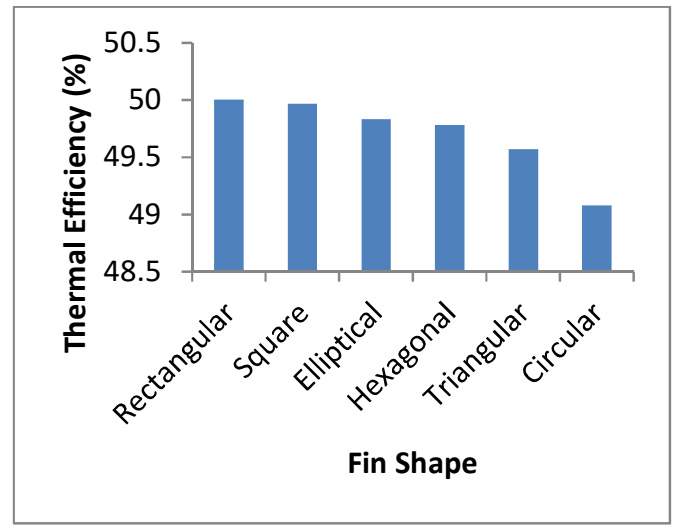

Fig. 7: Thermal efficiency of the different fin shapes

\section{REFERENCES}

Ekpu M., (2018). Effects of fins arrangement on thermal performance in microelectronics devices. J. Appl. Sci. Environ. Manage. 22(11), 17971800 .

Ekpu M., Bhatti R, Ekere N., Mallik S., Otiaba K. (2012). Effects of thermal interface materials (solders) on thermal performance of a microelectronic package. IEEE International Symposium on Design, Test, Integration, and Packaging of MEMS/MOEMS, Cannes Cote d' Azur, France, 25-27 April 2012, 154-159.

Ekpu M., Bhatti R., Ekere N.N., Mallik S., Amalu E., Otiaba K.C. (2011). Investigation of Effects of Heat Sinks on Thermal Performance of Microelectronic Package. $3^{\text {rd }}$ IEEE International 
Conference on Adaptive Science and Technology. Abuja, Nigeria 24-26 November 2011, 127-132.

Ekpu M., Bhatti R., Okereke M.I., Mallik S., Otiaba K.C. (2013). Prediction and Optimization of Design Parameters of Microelectronic Heat Sinks. J. Emerge. Trends Engineer. Appl. Sci. 4 (3), 493500 .

Incropera F.P., Dewitt D.P., Bergman T.I., Lavine A.S. (2007). Fundamentals of heat and mass transfer. $6^{\text {th }}$ Ed. United States of America, John Wiley and Sons, Inc., 2-925.

Kreutz E.W., Pirch N., Ebert T., Wester R., Ollier B., Loosen P., Poprawe R. (2000). Simulation of micro-channel heat sinks for optoelectronic microsystems. Microelectronics Journal, 31 (910), 787-790.

Kulkarni D.P., Das D.K. (2005). Analytical and numerical studies on microscale heat sinks for electronic applications. Appl. Thermal Engineer. 25 (14-15), 2432-2449.

Luo X., Xiong W., Cheng T., Liu S. (2009). Design and optimization of horizontally located plate fin heat sink for high power LED street lamps. Electronic Components and Technology Conference, p854-859.
Maveety J.G., Jung H.H. (2000). Design of an optimal pin-fin heat sink with air impingement cooling. International Communications in Heat and Mass Transfer, 27 (2), 229-240.

Maveety J.G., Jung H.H. (2002). Heat transfer from square pin-fin heat sinks using air impingement cooling. IEEE Transactions on Components and Packaging Technologies, 25 (3), 459-469.

Naphon P., Sookkasem A. (2007). Investigation on heat transfer characteristics of tapered cylinder pin fin heat sinks. J. Energy Conversion and Manage., 48 (10), 2671-2679.

Wan Z.M., Liu J., Su K.L., Hu X.H., M S.S. (2011). Flow and heat transfer in porous micro heat sink for management of high power LEDs. Microelectronics Journal, 42 (5), 632-637.

Yang Y., Peng H. (2008). Numerical study of pin-fin heat sink with un-uniform fin height design. International Journal of Heat and Mass Transfer, 51 (19-20), 4788-4796.

Yang Y., Peng H. (2009). Numerical study of the heat sink with un-uniform fin width designs. Intern. $J$. Heat and Mass Transfer. 52 (15-16), 3473-3480. 